\section{Ethephon with 1-Aminocyclopropane-1-Carboxylic Acid Can Defoliate Grapevines, and Thereby Improve Vine-drying of Grapes}

\author{
Thiago Vieira da Costa ${ }^{1}$, João Alexio Scarpare Filho ${ }^{1}$, and \\ Matthew W. Fidelibus ${ }^{2,3}$
}

AdDitional INDEX words. ACC, dry-on-vine, DOV, Vitis vinifera, leaf abscission, raisin

SUMMARY. In two experiments, various combinations of ethephon, with or without 1-aminocyclopropane carboxylic acid (ACC), were applied to the fruiting zone of 'Selma Pete' raisin grapes (Vitis vinifera) to determine whether any could serve as a defoliant, and if so, whether defoliation improved subsequent vine drying of the grapes. In the first experiment, the fruiting zone was treated on $8 \mathrm{Aug}$. 2013 with a control (water) and one of four plant growth regulator (PGR) treatments: $1000 \mathrm{ppm}$ ethephon, $1000 \mathrm{ppm}$ ethephon plus $1000 \mathrm{ppm}$ ACC, $2000 \mathrm{ppm}$ ethephon, and $2000 \mathrm{ppm}$ ethephon plus $1000 \mathrm{ppm}$ ACC. In the first experiment, treatment with any of the PGRs hastened leaf senescence, but leaf greenness, measured with a SPAD meter, declined most rapidly in leaves from vines treated with $2000 \mathrm{ppm}$ ethephon or $2000 \mathrm{ppm}$ ethephon plus $1000 \mathrm{ppm}$ ACC, and defoliation was best in vines treated with $2000 \mathrm{ppm}$ ethephon plus $1000 \mathrm{ppm}$ ACC. None of the treatments in the first study affected berry composition, hastened berry drying, or ultimately affected raisin moisture or quality. In a second experiment, initiated 18 days later, a factorial design was employed to determine whether three chemical treatments, a control (water spray), $2000 \mathrm{ppm}$ ethephon, and $2000 \mathrm{ppm}$ ethephon plus $1000 \mathrm{ppm}$ of ACC, might interact with fruiting zone orientation (east or west facing) to affect leaf senescence or berry drying. The second study confirmed that 2000 ppm ethephon and 2000 ppm ethephon plus 1000 ppm ACC induced rapid leaf senescence. Defoliation proceeded more rapidly in the second study and by 13 days after treatment, vines treated with 2000 ppm ethephon plus 1000 ppm ACC had less than one leaf layer remaining in the fruiting zone compared with more than 2.5 leaf layers in untreated vines. Treatments again had no effect on berry fresh weight or composition, but grapes on west-facing vines treated with $2000 \mathrm{ppm}$ ethephon plus $1000 \mathrm{ppm}$ ACC dried significantly better than grapes on vines subjected to other treatments, possibly because the higher temperatures of westfacing vines coupled with better defoliation of the $2000 \mathrm{ppm}$ ethephon plus $1000 \mathrm{ppm}$ ACC treatment was sufficient to improve grape drying compared with vines subjected to other trellis orientation and chemical treatment combinations. Therefore, we conclude that treatment with ethylene-promoting PGRs can defoliate the fruiting zone of 'Selma Pete' grapes with divided canopies, and such defoliation treatments may enhance berry drying when drying is initiated later than normal.

$\mathrm{C}$ alifornia's San Joaquin Valley has been a global leader in raisin production for more than a century (Fidelibus, 2014). Most of California's raisins are made from 'Thompson Seedless' grapes (Vitis vinifera) that are hand harvested onto paper trays and left in

This research was made possible by financial support from São Paulo Research Foundation (FAPESP).

We thank Valent BioSciences for providing 1-aminocyclopropane-1-carboxylic acid, and Shijian Zhuang and Lindsay Jordan, University of California Cooperative Extension, for reviewing an earlier draft of this manuscript

${ }^{1}$ Department of Horticulture, University of São Paulo, Piracicaba, SP, 13418-900, Brazil

${ }^{2}$ Department of Viticulture and Enology, University of California, Davis, CA 95616

${ }^{3}$ Corresponding author. E-mail: mwfidelibus@ucdavis.edu. the vineyard to dry. However, technological advances and economic and social changes increasingly favor adoption of mechanized production methods such as dry-on-vine (DOV) (Fidelibus, 2014). In DOV vineyards, grapevine canes bearing mature fruit are severed to initiate drying, and the grapes are left on the trellises to DOV (May and Kerridge, 1967). Grapes DOV more slowly than they dry on trays because temperatures in the canopy are lower than those at the soil surface (Christensen and Peacock, 2000). The slow drying rate is one disadvantage of the DOV method; raisins that have not dried to $<16 \%$ moisture by mid-October, which is generally considered to be the end of California's drying season, may have to be finish dried, increasing production costs (Fidelibus et al., 2007). In Australia, an alkaline drying emulsion is used to hasten drying and to help preserve the light color typical of Sultana raisins (Clingeleffer, 2011; Grncarevic and Lewis, 1976). However, drying emulsion is not widely used in California because a darkcolored "natural" raisin is preferred. Thus, in California, the risk of inadequate drying is primarily managed by initiating cane severance as soon as fruit have amassed $\geq 20 \%$ soluble solids (Parpinello et al., 2012).

Raisin grapes that ripen earlier than 'Thompson Seedless', such as 'Selma Pete', have been selected for DOV (Fidelibus et al., 2008). Prompt cane severance of early-ripening varieties greatly increases the likelihood of adequate drying (Parpinello et al., 2012), but additional measures may be beneficial in years when grapes ripen later than normal, or when atypically cool or wet weather occurs during the normal drying period. Drying should be hastened by canopy management practices that increase fruit exposure to the sun. Practices such as separating fruit-bearing canes from sterile renewal shoots and defoliation of the fruiting zone have been suggested as possible ways to improve fruit drying (Fidelibus et al., 2007; Peacock and Swanson, 2005). Separating the canopy may prevent leaves on renewal shoots from shading fruit, and defoliating shoots on fruiting canes should further expose

\begin{tabular}{llll}
\hline $\begin{array}{l}\text { Units } \\
\text { To convert U.S. to SI, } \\
\text { multiply by }\end{array}$ & U.S. unit & SI unit & $\begin{array}{l}\text { To convert SI to U.S., } \\
\text { multiply by }\end{array}$ \\
\hline 10 & $\%$ & $\mathrm{~g} \cdot \mathrm{L}^{-1}$ & 0.1 \\
0.3048 & $\mathrm{ft}$ & $\mathrm{m}$ & 3.2808 \\
3.7854 & $\mathrm{gal}$ & $\mathrm{L}$ & 0.2642 \\
0.4536 & $\mathrm{lb}$ & $\mathrm{kg}$ & 2.2046 \\
28.3495 & $\mathrm{oz}$ & $\mathrm{g}$ & 0.0353 \\
1 & $\mathrm{ppm}$ & $\mathrm{mg} \cdot \mathrm{L}^{-1}$ & 1 \\
$\left({ }^{\circ} \mathrm{F}-32\right) \div 1.8$ & ${ }^{\circ} \mathrm{F}$ & ${ }^{\circ} \mathrm{C}$ & $\left({ }^{\circ} \mathrm{C} \times 1.8\right)+32$
\end{tabular}


clusters of fruit to the sun since most leaves on severed canes do not abscise, even after they become desiccated. Fidelibus et al. (2007) observed that canopy separation and defoliation methods interacted with each other and with drying conditions to affect drying of 'Thompson Seedless' grapes on traditional trellises. For example, burning or blowing dead leaves from the vines only improved berry drying on vines with divided canopies in a year with poor drying conditions, and not in two other years with better conditions (Fidelibus et al., 2007). Moreover, leaf blowing sometimes increased moldiness of dried fruit, and a grower reported that burning did the same, apparently because these defoliation methods may damage drying fruit (Fidelibus et al., 2007).

The PGR ethephon was also tested as a potential defoliant for 'Thompson Seedless', but the highest concentration tested, $750 \mathrm{ppm}$, had no obvious effect on fruit or foliage (Fidelibus et al., 2007). However, higher rates of ethephon have been shown to be an effective postharvest defoliant of grapevines in tropical areas (Fracaro and Boliani, 2001), suggesting that ethylene-promoting PGRs can defoliate grapevines if sufficiently high concentrations are used. Application of ACC, a naturally occurring biochemical precursor of ethylene, with ethephon might improve efficacy or enable the use of lower rates. To our knowledge, ACC has not been tested as a defoliant of grapevines, but ethephon and ACC were found to have similar effects on olive fruit abscission (Burns et al., 2008).

Regardless of how vines are defoliated, it is important that only fruit-bearing shoots from canes, the leaves on which account for $\approx 50 \%$ of vine canopy (Scholefield et al., 1977), are defoliated. Shoots on canes are killed by cane severance anyway, and vines can annually sustain such damage with minimal effects on future productivity (Scholefield et al., 1977). However, additional defoliation (i.e., $>50 \%$ ) can reduce vine vigor and yield in subsequent seasons (Scholefield et al., 1977). Therefore, defoliants should be applied in a manner that maximizes coverage of fruiting zone foliage, to optimize efficacy, and minimizes contact with non-target foliage or fruit. The Shaw swingarm

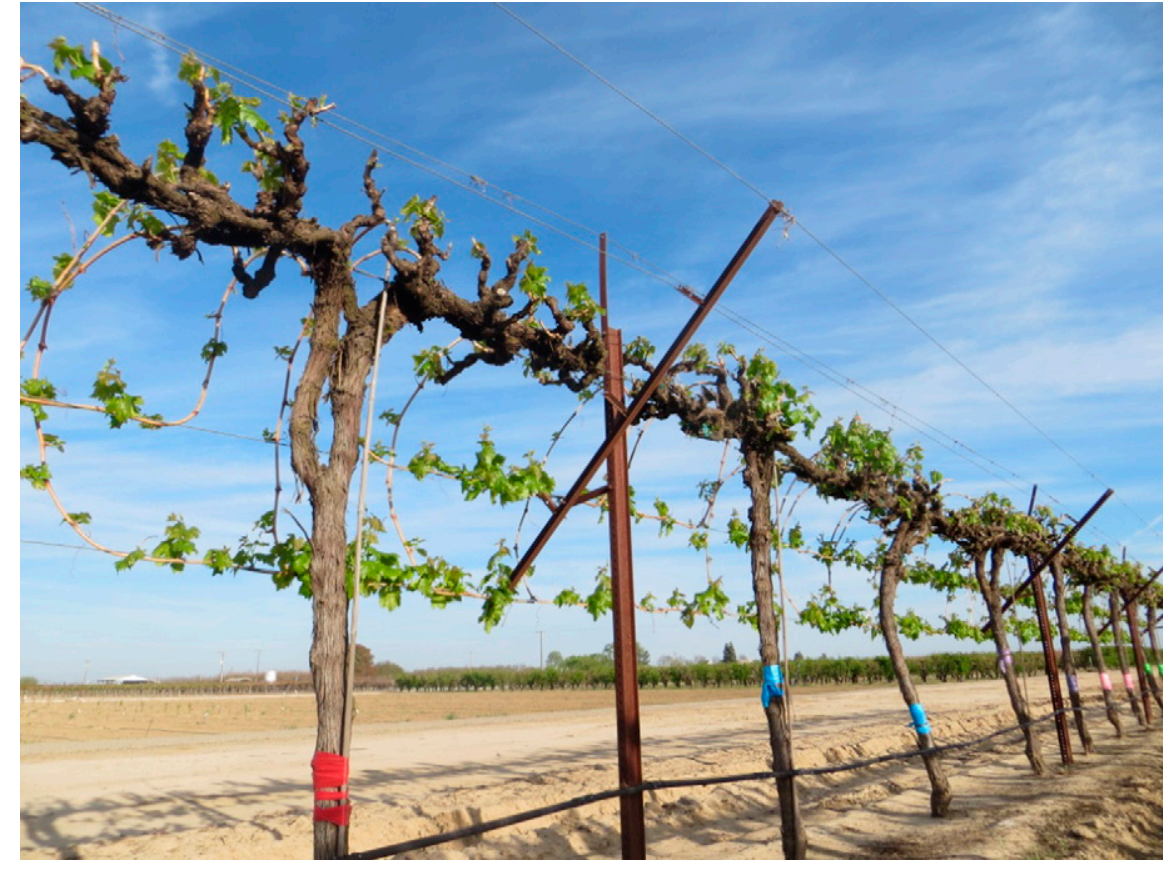

Fig. 1. Shaw swingarm trellis system at Kearney Agricultural Center, Parlier, CA.

trellis (Shaw, 2000) has design features that could be ideal for such an application. The canopy can be clearly divided into fruiting and renewal zones by tying fruiting canes to the lower half of the sloping $\mathrm{T}$-shaped cross arm and directing renewal shoots toward the upper half, allowing sprays to be restricted to the fruiting zone. Further, clusters of mature fruit hang below the foliage, so a PGR spray from above the canopy could achieve excellent coverage of leaves, which would somewhat shield fruit from direct spray contact. The primary objectives of this research were to determine whether ethylene-promoting PGRs might have potential to defoliate fruiting shoots of 'Selma Pete' and, if so, whether defoliation improved DOV of 'Selma Pete' raisin grapes on a Shaw swingarm trellis.

\section{Materials and methods}

In 2013 , two studies were conducted on 'Selma Pete' grapevines grafted to 'Harmony' [ $V$. champinii $\times$ $(V$. solonis $\times V$. othello $)]$ rootstocks, at the University of California Kearney Agricultural Center, Parlier, CA (lat. $36.598^{\circ} \mathrm{N}$, long. $119.503^{\circ} \mathrm{W}, 344-\mathrm{ft}$ elevation). Vines were planted in 2000 at a $6.5 \times 11.5$-ft spacing (within and between rows, respectively) trained to bilateral cordons, and supported by a Shaw swingarm trellis (Fig. 1) (Shaw, 2000) in rows oriented north to south. The 3 -ft-long bilateral cordons were supported by a wire attached at $5.5 \mathrm{ft}$ aboveground level to 6 - $\mathrm{ft}$-tall vertical steel stakes. At this height, the cordon wire nearly bisects a 9-ft-long crossarm that is also attached to the stake at a point just below the cordon wire. Each crossarm is bolted to a stake at its midpoint, and braces are used to fix the arms at a $50^{\circ}$ angle. The crossarms support four parallel wires, two above the cordon wire and two below, each spaced 1.28 and $2.45 \mathrm{ft}$ from the center of the arm. Fruiting canes are tied to the wires below the cordon wire and, in spring, a movable rake wire attached to the tip of masts on each stake is pivoted toward the top of the trellis to guide renewal shoots away from the fruiting section. Arms on adjacent rows are inclined in opposite directions (i.e., east or west facing on north-south rows) to help ensure even raisin drying across the vineyard. In Winter 2013, all vines were pruned to six 15 -node canes, and canes were tied to two foliage wires below the cordon wires. Trellis design features and cane arrangement are shown in Fig. 1.

The first experiment was initiated on 8 Aug. 2013. Pairs of adjacent vines were assigned to receive one of the following treatment solutions: control 
(water spray), $1000 \mathrm{ppm}$ ethephon (Ethrel $^{\circledR}$; Bayer CropScience, Research Triangle Park, NC), 1000 ppm ethephon plus 1000 ppm ACC (Valent BioSciences, Libertyville, IL), 2000 ppm ethephon, and 2000 ppm ethephon plus 1000 ppm ACC, in a randomized complete block (RCBD) design, replicated six times. Blocking was used in this trial to account for different trellis orientations (east or west facing). All solutions included $0.05 \%(\mathrm{v} / \mathrm{v})$ spreader-sticker (Latron B-1956; Loveland Industries, Greely, $\mathrm{CO})$. Treatments were intended to bracket a range of concentrations we thought might be effective based on the limited amount of defoliation data available from studies conducted with ethephon only (Fidelibus et al., 2007; T.V. da Costa, unpublished data).

The day before vines were treated, a sample of 30 berries was randomly collected from clusters in each twovine plot. Berries in each sample were counted, weighed, and then homogenized in a blender. Juice was filtered and total soluble solids measured with a temperature-compensating digital refractometer (PAL-1; Atago-USA, Bellevue, WA). Juice $\mathrm{pH}$ and titratable acidity were determined with an automatic titrator (DL 50; Mettler Toledo, Columbus, $\mathrm{OH}$ ), using 0.10 $\mathrm{N}$ sodium hydroxide and an endpoint of $8.2 \mathrm{pH}$. Berry soluble solids were found to be $>20 \%$, the minimum needed to make raisins (Parpinello et al., 2012), so the experiments commenced. Solutions were applied between 0730 and 0830 HR with a motorized backpack sprayer (Solo, Newport News, RI). Every plot received $\approx 1.15 \mathrm{~L}$ of the appropriate chemical solution. Sprays were directed to foliage on fruiting canes, leaving renewal shoots untreated.

A SPAD meter (SPAD-502; Konica Minolta, Osaka, Japan) was used to monitor changes in leaf greenness, as an indication of senescence, from 10 leaves (one measurement per leaf) in the fruiting zone of each plot. The average of 10 measurements per plot was used for statistical analysis. Measurements were performed at $0800 \mathrm{HR}$ on each of $14 \mathrm{~d}$ between spray application and cane severance.

Point-quadrat measurements (Smart and Robinson, 1991) were made in the fruiting zone of each vine $\mathrm{l} d$ before spray application, and again 9 and $14 \mathrm{~d}$ after application to monitor defoliation. The measurements were made by passing a sharp steel rod through the canopy at 20 points, each 4 inches along a horizontal transect in the middle of the fruit zone of each plot. The number of leaf and cluster layers was calculated by dividing the number of contacts with leaves or clusters by the number of passes. Canopy leaf temperature was measured daily for $14 \mathrm{~d}$ with a handheld infrared (IR) thermometer (model 39650-04; Cole-Parmer, Chicago, IL).
Infrared thermometer measurements were made by directing the instrument at the exterior of the treated canopy surface at $1300 \mathrm{HR}$, using an average of three measurements per plot. Ambient temperatures throughout the study periods were recorded by an onsite weather station (KAC), and downloaded from an internet database (California Weather Data, 2015)

Fruiting canes on vines in each plot were severed $14 \mathrm{~d}$ after chemical treatments were applied to initiate fruit drying. By 26 Sept., grapes in

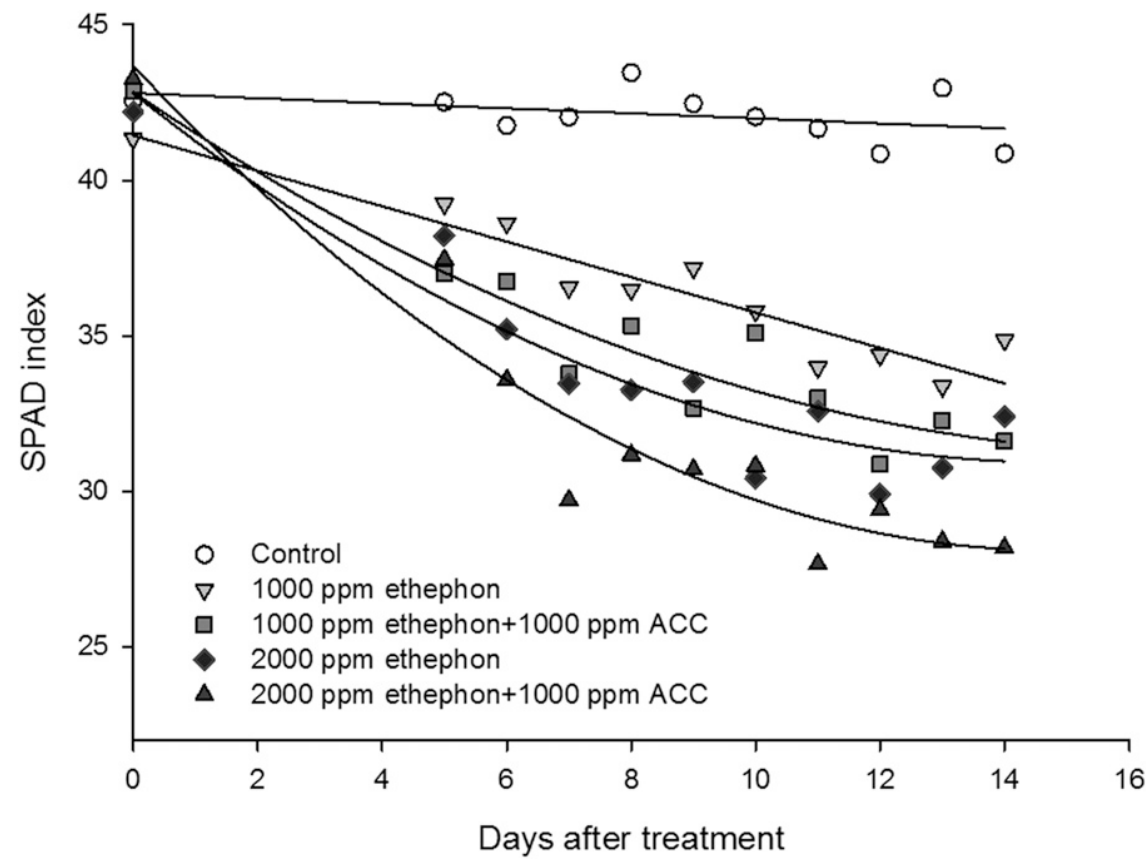

Fig. 2. Linear and quadratic regression from average daily SPAD index of leaves from 'Selma Pete' grapevines subjected to ethephon and 1-aminocyclopropane-1carboxylic acid (ACC) sprays on 8 Aug. in Parlier, CA. Regression equation: T1 = control: $\mathrm{y}=-0.1052 \mathrm{x}+42.726, \mathrm{R}^{2}=0.19 ; \mathrm{T} 2=1000$ ppm ethephon: $\mathrm{y}=$ $-0,6761 x+40,579, \mathrm{R}^{2}=0.84 ; \mathrm{T} 3=1000 \mathrm{ppm}$ ethephon $+1000 \mathrm{ppm}$ ACC: $\mathrm{y}=0.121 \mathrm{x}^{2}-2.3125 \mathrm{x}+42.97, \mathrm{R}^{2}=0.82 ; \mathrm{T} 4=2000$ ppm ethephon: $\mathrm{y}=$ $0.1901 \mathrm{x}^{2}-3.1853 \mathrm{x}+44.175 \mathrm{R}^{2}=0.92 ; \mathrm{T} 5=2000 \mathrm{ppm}$ ethephon $+1000 \mathrm{ppm}$ ACC: $\mathrm{y}=-5.971 \ln (\mathrm{x})+41.348, \mathrm{R}^{2}=0.90 ; 1 \mathrm{ppm}=1 \mathrm{mg} \cdot \mathrm{L}^{-1}$.

Table 1. Leaf layers in 'Selma Pete' grapevines, subjected to ethephon and 1aminocyclopropane-1-carboxylic acid (ACC) sprays on 0,9 , and $14 \mathrm{~d}$ after treatment (8 Aug. 2013) in Parlier, CA.

\begin{tabular}{lccc}
\hline & \multicolumn{3}{c}{ Leaf layers (no.) } \\
\cline { 2 - 4 } Treatment $^{\mathrm{z}}$ & \multicolumn{3}{c}{ Days after treatment } \\
\cline { 2 - 4 } Control & $\mathbf{0}$ & $\mathbf{9}$ & $\mathbf{1 4}$ \\
$1000 \mathrm{ppm}$ ethephon & $2.31^{\mathrm{y}}$ & 2.24 & $2.82 \mathrm{~b}$ \\
$1000 \mathrm{ppm}$ ethephon +1000 ppm ACC & 2.11 & 2.40 & $2.17 \mathrm{ab}$ \\
$2000 \mathrm{ppm}$ ethephon & 2.27 & 2.48 & $2.08 \mathrm{ab}$ \\
$2000 \mathrm{ppm}$ ethephon +1000 ppm ACC & 2.37 & 2.30 & $1.73 \mathrm{a}$ \\
\hline
\end{tabular}

${ }^{\mathrm{z}} 1 \mathrm{ppm}=1 \mathrm{mg} \cdot \mathrm{L}^{-1}$

'Values are treatment means $(n=6)$. Means followed by a different letter, within columns, are significantly different according to Tukey's test $(P<0.05)$. 
Table 2. Number of clusters, cluster abscission, raisin yield, moisture content, and "B and Better" and "Substandard" grades from 'Selma Pete' grapevines subjected to ethephon and 1-aminocyclopropane-1-carboxylic acid (ACC) sprays on 8 Aug. and harvested on 26 Sept. 2013 in Parlier, CA.

\begin{tabular}{|c|c|c|c|c|c|c|}
\hline Treatment $^{\mathrm{z}}$ & $\begin{array}{c}\text { Clusters } \\
\text { (no./vine) }\end{array}$ & $\begin{array}{c}\text { Cluster } \\
\text { abscission (\%) }\end{array}$ & $\begin{array}{c}\text { Yield } \\
(\mathrm{kg} / \text { vine })^{\mathrm{z}}\end{array}$ & Moisture (\%) & $\begin{array}{l}\text { Quality (\% B } \\
\text { and Better) }\end{array}$ & Substandard (\%) \\
\hline Control & $58.83^{\mathrm{y}}$ & $0.50 \mathrm{ab}$ & 6.85 & $13.16^{\mathrm{z}}$ & 84.17 & 4.75 \\
\hline 1000 ppm ethephon & 53.16 & $0.33 \mathrm{~b}$ & 5.64 & 12.75 & 80.75 & 4.02 \\
\hline 1000 ppm ethephon + 1000 ACC & 59.66 & $0.66 \mathrm{ab}$ & 7.15 & 13.50 & 86.89 & 4.43 \\
\hline 2000 ppm ethephon & 54.66 & $0.66 \mathrm{ab}$ & 5.70 & 13.58 & 76.81 & 6.52 \\
\hline 2000 ppm ethephon + 1000 ACC & 58.66 & $1.33 \mathrm{a}$ & 6.83 & 13.25 & 78.94 & 4.65 \\
\hline
\end{tabular}

${ }^{\mathrm{z}} \mathrm{l} \mathrm{ppm}=1 \mathrm{mg} \cdot \mathrm{L}^{-1}, \mathrm{l} \mathrm{kg}=2.2046 \mathrm{lb}$.

'Values are treatment means $(\mathrm{n}=6)$. Mean followed with no letter suggest no difference, according to Tukey's test $(P<0.05)$.

all plots had appeared to dry to $<16 \%$ moisture, the maximum acceptable moisture content of raisins, so clusters of dried grapes were harvested and weighed. At harvest, the number of clusters in each plot was counted. On some treated vines we observed that a few whole clusters had developed an abscission layer on their peduncles and detached from the vine. Any abscised clusters were counted, and the percentage of abscised clusters determined by dividing the number of abscised clusters by the total number of clusters in the plot. A 2-kg subsample of raisins from each plot was collected and sealed in a polyethylene bag and retained for moisture and quality measurements. Approximately $500 \mathrm{~g}$ of each raisin subsample was ground into a paste with a meat grinder (MO-33; General Slicing, Murfreesboro, TN), and moisture content of the paste was estimated using a dried fruit moisture meter (DFA Moisture Testers, Sacramento, CA). Approximately $1 \mathrm{~kg}$ of raisins was subjected to air-stream sorter analyses to determine " $\mathrm{B}$ and better" and "substandard" raisin grades (Fisher et al., 1961).

All vines were pruned to six 15node canes in Winter 2014, and all prunings from each plot were collected into paper bags and dried at $60{ }^{\circ} \mathrm{C}$ until they attained a constant weight at which time they were weighed. Prunings were dried because they contained a mixture of fresh and partially dried prunings (because of cane severance to initiate grape drying). On 27 Feb. 2014, the total number of buds in each plot was counted, and the number of nodes with an emerging shoot was scored daily in each plot until a constant number was attained, after which time percent budbreak was calculated. Budbreak date was considered as the date when $50 \%$ percent of the

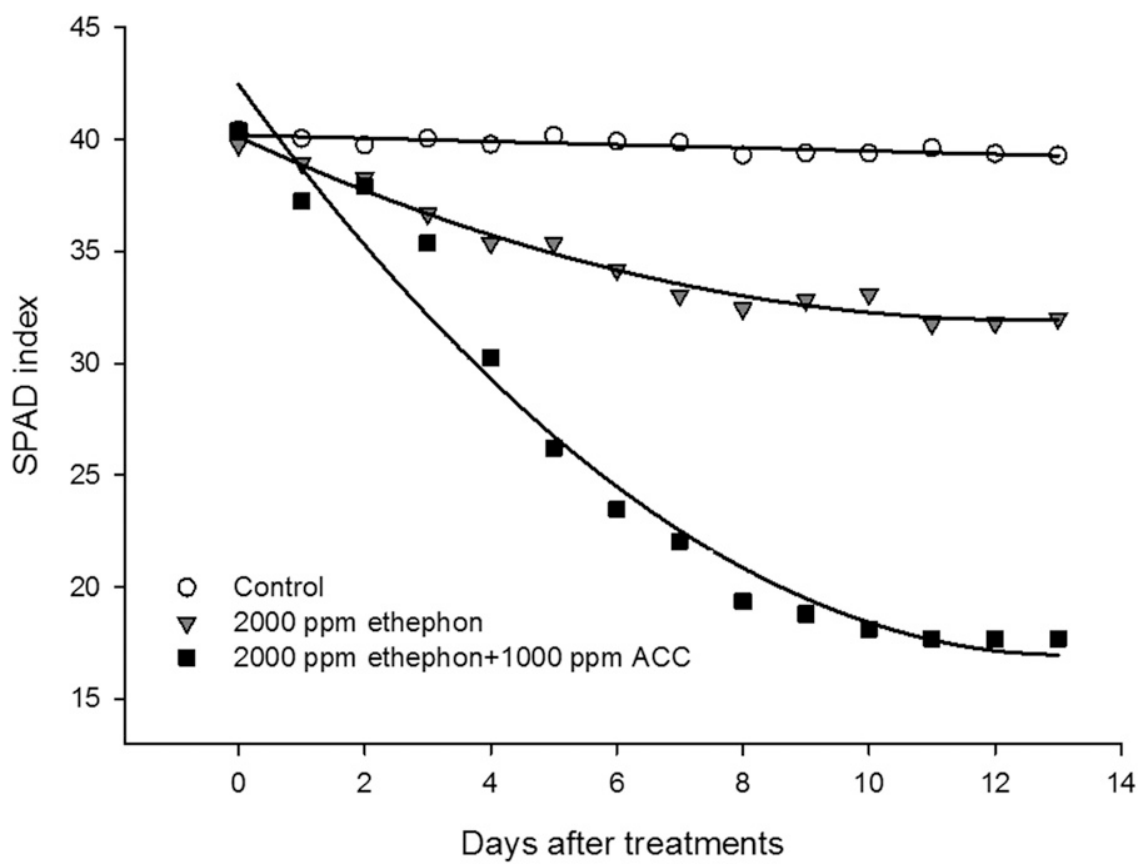

Fig. 3. Linear and quadratic regression of average daily SPAD index of leaves from 'Selma Pete' grapevines subjected to ethephon and 1-aminocyclopropane-1carboxylic acid (ACC) sprays on 26 Aug. in Parlier, CA; $1 \mathrm{ppm}=1 \mathrm{mg} \cdot \mathrm{L}^{-1}$.

nodes, from which green shoots were observed, had attained budbreak.

Early cane severance is critically important in DOV raisin production because drying conditions deteriorate as daylengths and daily average temperatures decrease, yet drying cannot commence until berries have amassed enough sugar to optimize yield and quality (Parpinello et al., 2012). Because delayed cane severance negatively effects drying, drying aids may be more important when canes are severed late than when they are severed early. Therefore, a second experiment was initiated on 26 Aug. 2013. In the first study, which was blocked by trellis orientation, it was observed that the treated leaves on west-facing vines seemed to senesce more quickly than leaves on east-facing vines, so a factorial design was employed in the second study to test the possible interaction of chemical treatments, including control (water spray), 2000 ppm ethephon, and 2000 ppm ethephon plus $1000 \mathrm{ppm}$ of ACC (each with $0.05 \%$ Latron B-1956 stickerspreader), with canopy aspect, (east or west facing). Treatments were again applied to pairs of adjacent vines using the same technique and equipment as described in the first study. The same environmental and plant measurements made in the first study were repeated in the second study using the same time intervals.

Because of the later cane treatment and cane severance dates of the second study, most grapes did not dry adequately by 21 Oct., when they were harvested. Grapes were harvested 
before they had fully dried because favorable drying weather was no longer forecast and further environmental exposure was likely to result in spoilage. Therefore, partially dried grapes were harvested as in the first study. Some of these grapes were too moist to use a dried fruit moisture meter, so a subsample of raisins was weighed, put in a forced air oven (model T35HV216; Gruenberg Oven, Williamsport, PA) at $60^{\circ} \mathrm{C}$, and dried to a constant weight. Moisture content was then determined gravimetrically using a balance (model FG-60KAM; A\&D Co., Tokyo, Japan). A second sample of partially dried grapes from each plot was also placed in a forced air oven, but only until fruit appeared to dry to between $9 \%$ and $16 \%$ moisture, the range of moisture content needed to make valid quality measurements with an air stream sorter. Moisture content of each grape sample was confirmed with a dried fruit moisture meter, and their quality grades were determined with air stream sorter analyses (Fisher et al., 1961).

Data analyses for both trials were performed using SAS (version 9.2; SAS Institute, Cary, NC) and SigmaPlot (version 10; Systat Software, San Jose, CA). Results were tested for homogeneity of variance and subjected to analysis of variance. Means were compared by Tukey's test $(P<0.05)$.

\section{Results and discussion}

FirsT STUDY. Untreated control leaves exhibited a gradual linear decline in SPAD values across the 2 -week period between spray application and cane severance (Fig. 2). In contrast, SPAD values of leaves treated with $1000 \mathrm{ppm}$ ethephon declined more rapidly, though also in a linear fashion. Leaves of vines treated with $1000 \mathrm{ppm}$ ethephon plus 1000 ppm ACC or 2000 ppm ethephon responded with a similar quadratic reduction in SPAD values, suggesting ACC may have a similar potency as ethephon, at least when coapplied, as was the case in this study. Treatment with $2000 \mathrm{ppm}$ ethephon plus 1000 ppm ACC also resulted in a quadratic reduction in SPAD values, but values declined at a more rapid rate compared with other treatments. Defoliation proceeded more slowly than the decline in SPAD values, and treatments did not affect leaf layer numbers until $14 \mathrm{~d}$ after treatment (DAT) (Table 1). By then, vines treated with $2000 \mathrm{ppm}$ ethephon, or 2000 ppm ethephon plus 1000 ppm ACC had fewer leaf layers than vines subjected to other treatments (Table 1). Leaves on renewal shoots retained a normal appearance and did not abscise, regardless of treatment (personal observation).

Before treatment, berry weights ranged from 1.61 to $1.71 \mathrm{~g} /$ berry, soluble solids averaged about $23 \%$, and titratable acidity ranged from 5.4 to $5.8 \mathrm{~g} \cdot \mathrm{L}^{-1}$. By $14 \mathrm{DAT}$, average berry weight declined slightly to between 1.53 and $1.68 \mathrm{~g} /$ berry, and soluble solids increased to $24.5 \%$ to $26.75 \%$, titratable acidity remained about the same as before, and no treatments affected berry mass or composition (data not shown). The slight decrease in berry weight and increase in soluble solids suggest berries were slowly desiccating, although canes had not yet been severed (cane severance immediately followed the 14 DAT sample collection). This is consistent with previous observations that the berries of some DOV varieties, including 'Selma Pete', have a tendency to desiccate after ripening (Aung et al., 2002; Fidelibus, 2014). Ethephon may be used to hasten ripening of raisin grapes (Szyjewicz et al., 1984); the fact that none of the treatments increased soluble solids in this trial is likely because fruit already had amassed a high level of soluble solids at treatment and thus may have already been fully ripe.

Table 3. Leaf layers in 'Selma Pete' grapevines, subjected to ethephon and 1 aminocyclopropane-1-carboxylic acid (ACC) sprays on 0,7 , and $13 \mathrm{~d}$ after treatment (26 Aug. 2013) in Parlier, CA.

\begin{tabular}{lccr}
\hline & \multicolumn{3}{c}{ Leaf layers (no.) } \\
\cline { 2 - 4 } Treatment $^{\mathrm{z}}$ & \multicolumn{3}{c}{ Days after treatment } \\
\cline { 2 - 4 } Control & $\mathbf{0}$ & 7 & $\mathbf{1 3}$ \\
2000 ppm ethephon & $2.87^{\mathrm{y}}$ & $2.46 \mathrm{~b}$ & $2.65 \mathrm{c}$ \\
2000 ppm ethephon +1000 ppm ACC & 2.61 & $2.06 \mathrm{~b}$ & $2.05 \mathrm{~b}$ \\
\hline
\end{tabular}

${ }^{2} 1 \mathrm{ppm}=1 \mathrm{mg} \cdot \mathrm{L}^{-1}$

'Values are treatment means $(\mathrm{n}=4)$. Means followed by a different letter, within columns, are significantly different according to Tukey's test $(P<0.05)$.

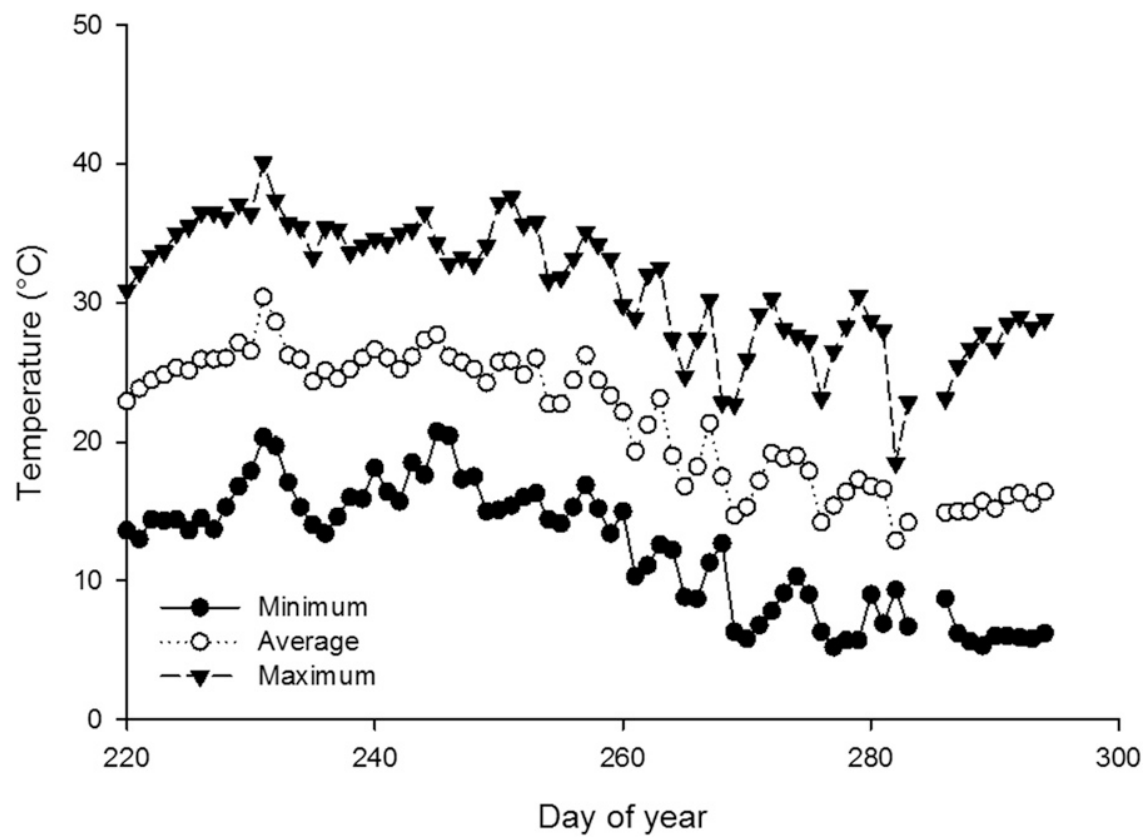

Fig. 4. Minimum, average, and maximum daily ambient temperatures at the Kearney Agricultural Center, Parlier, CA, during the course of the experiments, 8 Aug. (day of year 220) through 21 Oct. (day of year 294); $\left(1.8 \times{ }^{\circ} \mathrm{C}\right)+32={ }^{\circ} \mathrm{F}$. 
After $\approx 40$ DAT, abscised clusters were observed in some plots. The 2000 ppm ethephon plus $1000 \mathrm{ppm}$ ACC treatment induced more cluster abscission than other treatments, but not enough to influence the average number of clusters retained per vine or raisin yield at harvest (Table 2). Raisins were harvested from these plots in September, and moisture content and quality were acceptable and unaffected by treatments (Table $2)$. Both findings are understandable, as drying conditions during the first study were excellent (Fig. 3), and treatments did not affect soluble solids levels, a variable which has a dominating influence on raisin quality (Parpinello et al., 2012). In 2014, the season following treatment, shoot emergence began on 27 Feb. 2014, reaching $70 \%$ by 5 Mar. 2014. None of the treatments affected the rate of percent budbreak, or overall percent budbreak.

SeCOND STUdy. The $2000 \mathrm{ppm}$ ethephon and $2000 \mathrm{ppm}$ ethephon plus 1000 ppm ACC treatments induced a rapid decline in SPAD values (Fig. 3), confirming the findings of our previous study. After $14 \mathrm{~d}$, fruiting zone leaves on vines treated with 2000 ppm ethephon had $19.5 \%$ lower SPAD values than those of leaves on untreated vines, and vines treated with $2000 \mathrm{ppm}$ ethephon plus 1000 ppm ACC had SPAD values that were $56.2 \%$ lower than those of untreated vines. These findings are similar to those in the previous study where identical treatments reduced SPAD values by $26 \%$ an $65 \%$, respectively. Defoliation proceeded more rapidly than in the previous study, and treatment effects were noted on 7 and 13 DAT. By 13 DAT, vines treated with 2000 ppm ethephon and 1000 ppm ACC had less than one leaf layer in the fruiting zone compared with more than 2.5 leaf layers in untreated vines (Table 3). Better defoliation observed in the second study may be because leaves were slightly older. Older leaves generally have lower auxin levels in the abscission zone, which makes them more sensitive to ethylene action (Beyer, 1975).

Treatments had no effect on berry weight, soluble solids, or titratable acidity, before or after the treatment, as observed in the previous study. Berry weight, soluble solids, and titratable acidity ranged from
1.64 to $1.70 \mathrm{~g}, 26.7 \%$ to $27.9 \%$, and 5.3 to $6.3 \mathrm{~g} \cdot \mathrm{L}^{-1}$, respectively, before treatments, and $1.58 \mathrm{~g}, 26.6 \%$, and $3.9 \mathrm{~g} \cdot \mathrm{L}^{-1}$, respectively, on 14 DAT. These data also suggest berries desiccated slightly during the observation period before cutting the canes.

Because of later cane severance date of the second study, daylengths and temperatures were declining (Fig. 4), and grapes did not dry as well as they did in the first study. Slow drying and forecasted poor drying conditions made it necessary to harvest the raisins before most of them had dried to below the maximum allowable moisture content of $16 \%$ (Table 4). Treatment effects on grape drying depended on grapevine canopy orientation. Treatments did not

affect grape moisture contents on vines with east-facing canopies, but treatment with $2000 \mathrm{ppm}$ ethephon plus 1000 ppm ACC significantly improved drying of grapes on vines with west-facing canopies (Table 4). The fruiting zone of west-facing vines experienced greater peak temperatures than the fruiting zone of eastfacing vines (Fig. 5), which were facing away from the sun during the hottest part of the day, in agreement with others (Spayd et al., 2002), who showed that clusters of grapes exposed to the west may attain much greater afternoon temperatures than clusters exposed to the east. Evidently, higher temperatures of west-facing vines coupled with the better defoliation of the $2000 \mathrm{ppm}$ ethephon plus

Table 4. Effect of plant growth regulator treatments and trellis orientation on moisture content of 'Selma Pete' grapevines in Parlier, CA.

\begin{tabular}{lcr}
\hline & \multicolumn{2}{c}{ Moisture (\%) } \\
\cline { 2 - 3 } Treatment $^{\mathrm{z}}$ & \multicolumn{2}{c}{ Trellis orientation } \\
\cline { 2 - 3 } Control & East & West \\
2000 ppm ethephon & $17.00^{\mathrm{y}}$ & $21.67 \mathrm{a}$ \\
$2000 \mathrm{ppm}$ ethephon +1000 ppm ACC & 19.67 & $18.33 \mathrm{a}$ \\
\hline
\end{tabular}

${ }^{2} 1 \mathrm{ppm}=1 \mathrm{mg} \cdot \mathrm{L}^{-1}$

yalues are treatment means $(\mathrm{n}=4)$. Means followed by a different letter, within columns, are significantly different according to Tukey's test $(P<0.05)$.

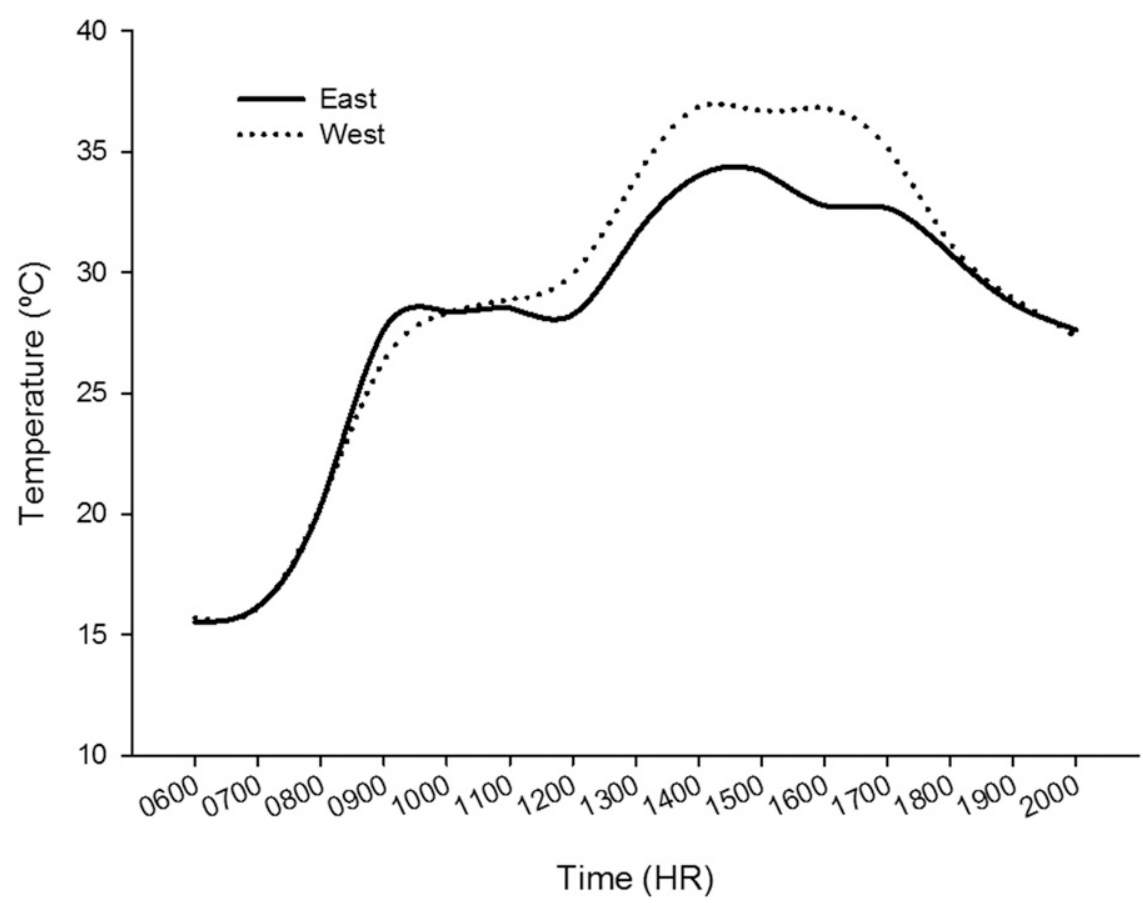

Fig. 5. Average temperature from 'Selma Pete' grapevine canopy surface in the middle of the fruit zone of each plot on vines oriented west or east, in north-south rows 29 Aug. 2013 in Parlier, CA; $\left(1.8 \times{ }^{\circ} \mathrm{C}\right)+32={ }^{\circ} \mathrm{F}$. 
Table 5. Number of clusters per vine, cluster abscission and yield of 'Selma Pete' grapevines subjected to ethephon and 1aminocyclopropane-1-carboxylic acid (ACC) sprays in Parlier, CA.

\begin{tabular}{lccc}
\hline Treatment $^{\mathrm{z}}$ & $\begin{array}{c}\text { Clusters } \\
\text { (no./vine) }\end{array}$ & $\begin{array}{c}\text { Cluster } \\
\text { abscission (\%) }\end{array}$ & $\begin{array}{c}\text { Yield } \\
(\mathbf{k g} / \text { vine })^{\mathrm{z}}\end{array}$ \\
\hline Control & $65.67^{\mathrm{y}}$ & 0.17 & 6.40 \\
$2000 \mathrm{ppm}$ ethephon & 57.00 & 0.83 & 5.34 \\
$2000 \mathrm{ppm}$ ethephon $+1000 \mathrm{ppm}$ ACC & 57.17 & 2.33 & 5.79 \\
\hline
\end{tabular}

${ }^{\mathrm{z}} 1 \mathrm{ppm}=1 \mathrm{mg} \cdot \mathrm{L}^{-1}, 1 \mathrm{~kg}=2.2046 \mathrm{lb}$.

yalues are treatment means $(\mathrm{n}=4)$. Mean followed with no letter suggest no difference, according to Tukey's test $(P<0.05)$.

1000 ppm ACC treatment was sufficient to improve grape drying compared with vines subjected to trellis orientation and chemical treatment combinations.

Some cluster abscission was once again observed beneath vines treated with $2000 \mathrm{ppm}$ ethephon plus $1000 \mathrm{ppm}$ ACC, but as in the first study, yield was unaffected (Table 5). Raisin quality was unaffected by row orientation, chemical treatment, or their interaction (data not shown). Pruning weights, rate of budbreak progression, and total overall budbreak in Spring 2014 were also unaffected by any of the treatment combinations (data not shown).

\section{Conclusions}

Treatments with ethylene plus ACC-promoting PGRs can selectively defoliate the fruiting zone of 'Selma Pete' grapes with divided canopies, and such defoliation treatments may enhance berry drying.

\section{Literature cited}

Aung, L.H., D.W. Ramming, and R. Tarailo. 2002. Changes in moisture, dry matter, and soluble sugars of dry-on-thevine raisins with special reference to sorbitol. J. Hort. Sci. Biotechnol. 77:100-105.

Beyer, E.M., Jr. 1975. Abscission: The initial effect of ethylene is in the leaf blade. Plant Physiol. 55:322-327.

Burns, J.K., L. Ferguson, K. Glozer, W.H. Krueger, and R.C. Rosecrance. 2008. Screening fruit loosening agents for black ripe processed table olives. HortScience 43:1449-1453.
California Weather Data. 2015. Retrieve data for Kearney_Ag_Ctr-01.P (KAC). 12 Mar. 2015. <http://www.ipm.ucdavis. edu/calludt.cgi/PCSTATIONDATA? $\mathrm{MAP}=$ fresno.html\&STN=Kearney_Ag_ Ctr-01.P1440\&SCALE=Daily $/>$.

Christensen, L.P. and W.L. Peacock. 2000. The raisin drying process, p. 207216. In: L.P. Christensen (ed.). Raisin production manual. Univ. California, Agr. Natural Resources, Oakland, CA.

Clingeleffer, P. 2011. Mechanization of grape production in Australian vineyards, p. 111-120. In: J.R. Morris and P.L. Brady (eds.). Vineyard mechanization: Development and status in the United States and in the major grape producing regions of the world. ASHS Press, Alexandria, VA.

Fidelibus, M.W. 2014. Grapevine cultivars, trellis systems, and mechanization of the California raisin industry. HortTechnology 24:285-289.

Fidelibus, M.W., L.P. Christensen, D.G. Katayama, and D.W. Ramming. 2008. Early-ripening grapevine cultivars for dryon-vine raisins on an open-gable trellis. HortTechnology 18:740-745.

Fidelibus, M.W., S.J. Vasquez, and K.A. Cathline. 2007. Canopy separation and defoliation do not improve the dry-onvine raisin-making method for 'Thompson Seedless' grapevines on traditional trellises. J. Amer. Pomol. Soc. 61:61-70.

Fisher, C.D., A.P. Sidwell, and C. Golumbic. 1961. Sorting raisins by the airstream method. U.S. Dept. Agr. Mktg. Res. Rept. 451

Fracaro, A.A. and A.C. Boliani. 2001. Efeito do ethephon em videira 'Rubi' (Vitis vinifera L.), cultivada na região noroeste do estado de São Paulo. Revista Brasileira de Fruticultura. 23:510-512.

Grncarevic, M. and W.J. Lewis. 1976. Drying of grapes in Australia. Food Technol. Austral. 28:66-67, 69-71, 76.

May, P. and G.H. Kerridge. 1967. Harvest pruning of Sultana vines. Vitis 6:390-393.

Parpinello, G.P., H. Heymann, S. Vasquez, K.A. Cathline, and M.W. Fidelibus. 2012. Grape maturity, yield, quality, sensory properties, and consumer acceptance of Fiesta and Selma Pete dry-on-vine raisins. Amer. J. Enol. Viticult. 63:212-219.

Peacock, W.L. and F.H. Swanson. 2005. The future of California raisins is drying on the vine. Calif. Agr. 59:70-74.

Scholefield, P.B., P. May, and T.F. Neales. 1977. Harvest pruning and trellising of Sultana vines. I. Effects on yield and vegetative growth. Sci. Hort. 7:115122.

Shaw, I. 2000. Shaw swingarm trellis: Maximum mechanisation in trellis dried grape production. Dept. Natural Resources Environ., Melbourne, Australia.

Smart, R. and M. Robinson. 1991. Sunlight into wine: A handbook for winegrape canopy management. Winetitles, Adelaide, Australia.

Spayd, S.E., J.M. Tarara, D.L. Mee, and J.C. Ferguson. 2002. Separation of sunlight and temperature effects on the composition of Vitis vinifera cv. Merlot berries. Amer. J. Enol. Viticult. 53:171-182.

Szyjewicz, E., N. Rosner, and W.M. Kliewer. 1984. Ethephon ((2-chloroethyl) phosphonic acid, Ethrel, CEPA) in viticulture-A review. Amer. J. Enol. Viticult. 35:117-123. 